\title{
Modeling and Simulation of Composite Materials for SLS-Based 3D Printing
}

\author{
Md Hazrat Ali, Gaziz Yerbolat, Anuar Abilgaziyev
}

Mechanical and Aerospace Engineering Department, Nazarbayev University in Nus-Sultan. Kabanbay batyr 53, 010000 Nur-Sultan. Kazakhstan. E-mail: md.ali@nu.edu.kz

This paper discusses the modeling and simulation results of a new multi-material for a cost-effective Selective Laser Sintering (SLS)-based 3D printer. As this technology utilizes several materials, the mechanical property analysis of multi-materials is crucial for manufacturing an object with the desired physical characteristics. Firstly, the development of a database of the SLS 3D printing materials is accomplished, and based on the mechanical properties of materials, this optimization technique is proposed. Secondly, enhancement of physical property by stiffeners is considered and based on the stiffening technology, and an alternative optimization method proposed. Finally, two different material minimization methods are discussed in this research. The first method is based on the embedded materials with desired mechanical properties for enhancing the mechanical properties of the printed objects, which are twice optimized by this method with increased material saving. The second method is designed to use stiffeners to improve the stiffness characteristics of the materials, and then, perform material optimization. This method is effective with more suitability to complex composite geometries. Thus, the methods help to reduce materials used as well as the production cost in 3D printing technology.

Keywords: Additive Manufacturing, 3D Printing, Composite Materials, Material Properties

\section{Introduction}

Material optimization is a widely used technique at the initial stage of manufacturing to minimize the development cost. With the existing FEA software, the optimization can be easily performed according to the boundary conditions applied to the structure. Relying on the data of one of the topology optimization software ParetoWorks, the product's weight reduction can reach more than $50 \%$ of the initial structure [1]. The restriction of the optimization is the requirement of fully established design rules, which is not yet defined for multi-material products [2]. Therefore, there is a need to develop a material optimization method and apply it to multi-material 3D-printed products to minimize the production cost. Furthermore, it should be integrated into the newly developed multi-material SLS 3D printers.

The material optimization can significantly increase specific mechanical properties of the printed object and enables fewer amounts of materials to achieve desired cost-effective results. A few techniques are proposed, such as solid Isotropic Microstructure with Penalization (SIMP) or multi-material interpolation schemes based on Rational Approximation on Material Properties (RAMP) as mentioned in [2]. Another proposed optimization method is Sigmund's 99-line MATLAB code, developed for educational purposes, which consists of 16 lines for mech independency and 35 lines for finite element code, with other lines for comments and additional loads. Tavakoli and
Mohseni implemented this code for the multi-material case. Analyzing this optimization MATLAB code, it is observed that materials' thorough analysis is required. SIMP optimization method used for shape optimization is implemented based on Rational Approximation on Material Properties, but it is merely for cellular structures and is not appropriate for composite materials [3]. FEM-based simulation analysis for the homogenization of fibers reinforced composite materials is discussed in [13]. The application of progressive materials for rapid prototyping technology such as paper, nylon, wax, resins, metals, and ceramics are elaborated in [14].

Similar to the studies mentioned above, current research is intended to analyze different methods of topology optimization. However, the focus is narrowed towards the assessment of composite polymer materials used in SLS 3D printing. Firstly, it is proposed a new concept of SLS 3D printing by the complex chamber, which will be used as a basis for following research analysis. Then, two different methods of material optimization by enhancing mechanical properties are considered with further material reduction. The first method is based on mechanical property analyzation and data development, whereas the second method is based on the use of various stiffeners. The last analysis of material reduction is performed by the Topology Optimization function in ANSYS commercial software considering the composite material characteristics. These methods utilize a previously developed database in SLS 3D printing, as discussed in [4]. 
Previous work [6] proposed a multi-material based SLS printing technique to maintain complex parameters and perform numerical calculations accurately.

In the first method, previously, material evaluation is performed by thoroughly analyzing each material separately under tensile, compressive, and transverse axial loads. After obtaining the results, materials were compared by their mechanical property characteristics and sorted by their stiffness criteria. Then, considering the advantages of the "complex chamber" of the new SLS 3D printer recreates possible layer-by-layer composite geometries in design software, which are actually can be printed in new concept SLS 3D printer. According to the performance of each material and by analyzation on a variety of geometries under modal analysis, the desired material combinations are derived. Therefore, the first method is referred to as being based on mechanical property analyzation and data development. This method of topology optimization states that material ordering and frequency of layerby-layer material changing have a considerable impact on mechanical characteristics of composite and on further its topological optimization.

The second method optimization is based on the improvement of the mechanical property of composites by implementing stiffeners on the surface of the flat plate and a cylindrical object and their further evaluation. For the flat plate, rectangular, L-shaped, and T-shaped stiffeners were introduced, whereas the cylindrical object was introduced with longitudinal and ring-type stiffeners. According to the results, the stiffness of the composite material can be significantly increased by implementing stiffeners, which will further lead to a minimization of material usage. The increase in the number of stiffeners defiantly increases the stiffness of composite; however, the objective is to define the possible efficient number of stiffeners for the reduction of material usage.

The last analysis of topology optimization based on the use of Topology Optimization function in ANSYS Mechanical software is performed to observe the results of the improvement of mechanical property by two methods. Also, to compare the results to come up with a certain statement. The Topology Optimization tool eliminates the regions in the material that are not subjected to any load and produces a lightweight and optimized structure, whereas the mechanical property prediction technique facilitates the optimization of the model by suggesting the most effective material combination in the composite material. In this study, it is illustrated the increase in the performance of Topology Optimization by twice by implementing the above mentioned two methods.

\section{Materials and Methods}

2.1 Developing 3D-beam finite element simulationbased mechanical property optimization technique

The first stage of the first method is the development of specific data containing the mechanical performance of materials under specific simulations. For the easiness, it was considered four polymer materials (discussed in section 4): Nylon Polyamide 12, 33\% Glass-filled Nylon Polyamide 6, Nylon Polyamide 6 Flame-Retardant and Polyetheretherketone PEEK. Tab. 1 represents the individual mechanical characteristics of these materials. Structural analysis was conducted to examine the stiffness of materials under different loads. The specimens shown in Fig. 1 are used to conduct the computational analysis of materials subject to tensile, compressive, and transverse axial loads. The main aim of this analysis was to determine the critical points of deformations and, thus, to define the stiffness of materials. The obtained data is going to be used for the construction of more relevant layerby-layer composite material and its study, including further reduction in material.

\begin{tabular}{|c|c|c|c|c|}
\hline $\begin{array}{c}\text { Mechanical Pro- } \\
\text { perties }\end{array}$ & $\begin{array}{l}\text { Nylon } \\
\text { PA12 }\end{array}$ & $\begin{array}{l}33 \% \text { Glass-filled Nylon } \\
\text { Polyamide } 6\end{array}$ & $\begin{array}{c}\text { Nylon Polyamide } 6 \\
\text { Flame-Retardant }\end{array}$ & $\begin{array}{l}\text { Polyetherether- } \\
\text { ketone PEEK }\end{array}$ \\
\hline Density & $\begin{array}{c}0.95 \\
\mathrm{~g} / \mathrm{cm}^{3}\end{array}$ & $1.39 \mathrm{~g} / \mathrm{cm}^{3}$ & $1.18 \mathrm{~g} / \mathrm{cm}^{3}$ & $1.37 \mathrm{~g} / \mathrm{cm}^{3}$ \\
\hline Young's modulus & $1820 \mathrm{MPa}$ & $8800 \mathrm{MPa}$ & $2540 \mathrm{MPa}$ & $3920 \mathrm{MPa}$ \\
\hline Poisson's ratio & 0.393 & 0.35 & 0.372 & 0.3779 \\
\hline Bulk modulus & $2.882 \mathrm{GPa}$ & $5.175 \mathrm{GPa}$ & $0.593 \mathrm{GPa}$ & $3.922 \mathrm{GPa}$ \\
\hline Shear modulus & $0.664 \mathrm{GPa}$ & $2.389 \mathrm{GPa}$ & $0.113 \mathrm{GPa}$ & $1.504 \mathrm{GPa}$ \\
\hline $\begin{array}{l}\text { Compressive } \\
\text { strength }\end{array}$ & $69.7 \mathrm{MPa}$ & $120 \mathrm{MPa}$ & $74.2 \mathrm{MPa}$ & $114 \mathrm{MPa}$ \\
\hline Tensile strength & $44,2 \mathrm{MPa}$ & $115 \mathrm{MPa}$ & $64.5 \mathrm{MPa}$ & $95 \mathrm{MPa}$ \\
\hline $\begin{array}{l}\text { Tensile ultimate } \\
\text { strength }\end{array}$ & $76,1 \mathrm{MPa}$ & $210 \mathrm{MPa}$ & 70.1 & $97.1 \mathrm{MPa}$ \\
\hline
\end{tabular}




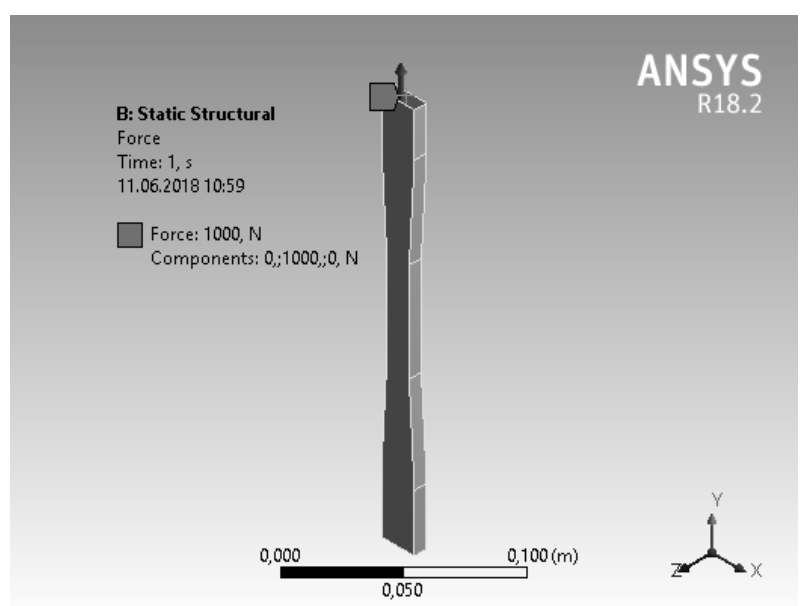

a)

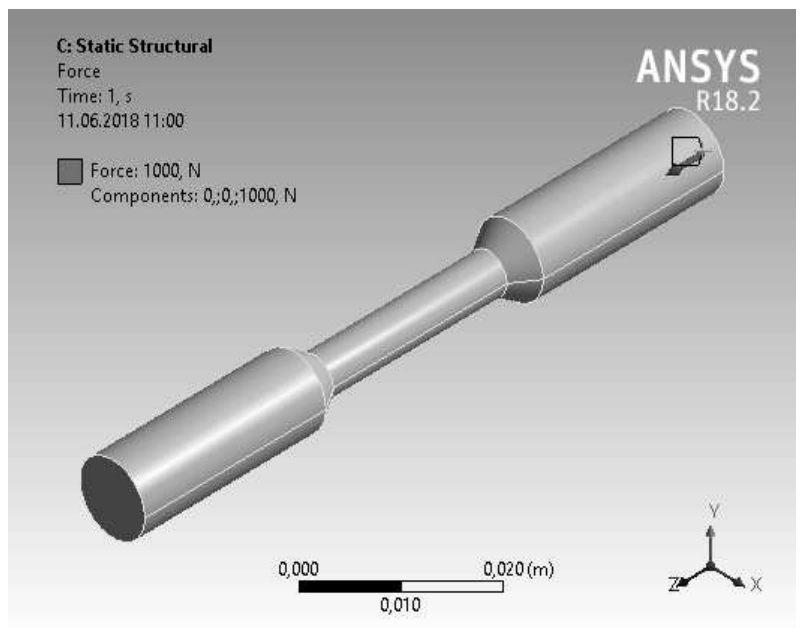

b)

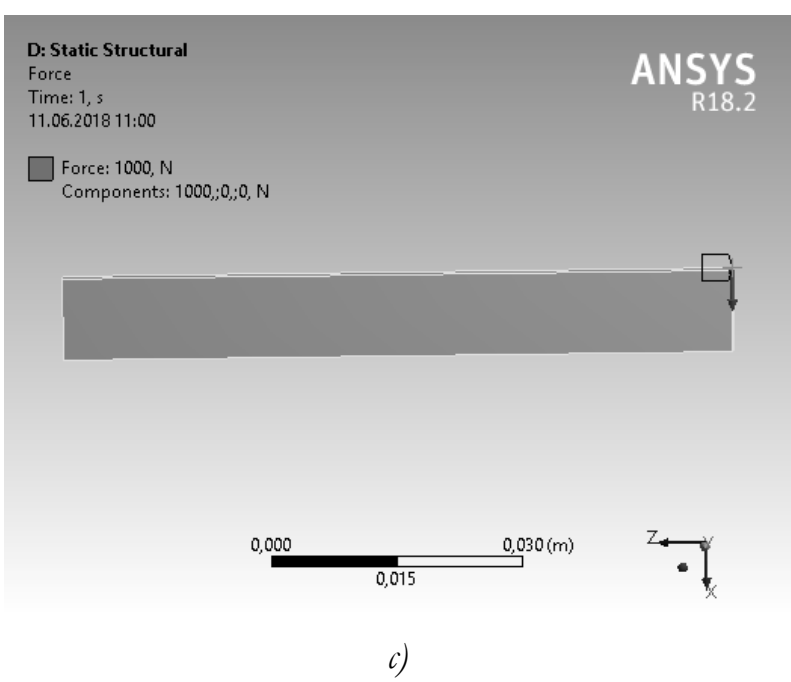

Fig. 1 (a) ASTM D638 tensile specimen; (b) Instron cylindrical compressive specimen; (c) Transverse axial load

$$
\Theta(t, T(t)) \equiv \int_{0}^{t} \frac{1}{T} \exp \left(-\frac{Q}{R T}\right) d t
$$

The geometries developed for this stage of the analysis are shown in Fig. 2 below.

The second stage of the first method is the analysis of layer-by-layer geometries developed under the proposed concept of SLS 3D printer. The thickness of the layers is $0.1 \mathrm{~mm}$, which is in the sintering range of the SLS printers. To approve the different layer connections in this paper, it was used the idea of Master Sintering Curve (MSC) proposed by Su and Johnson [7]. Each material has its melting temperature, which needs certain sintering process, which can be defined by the following Equation (1).

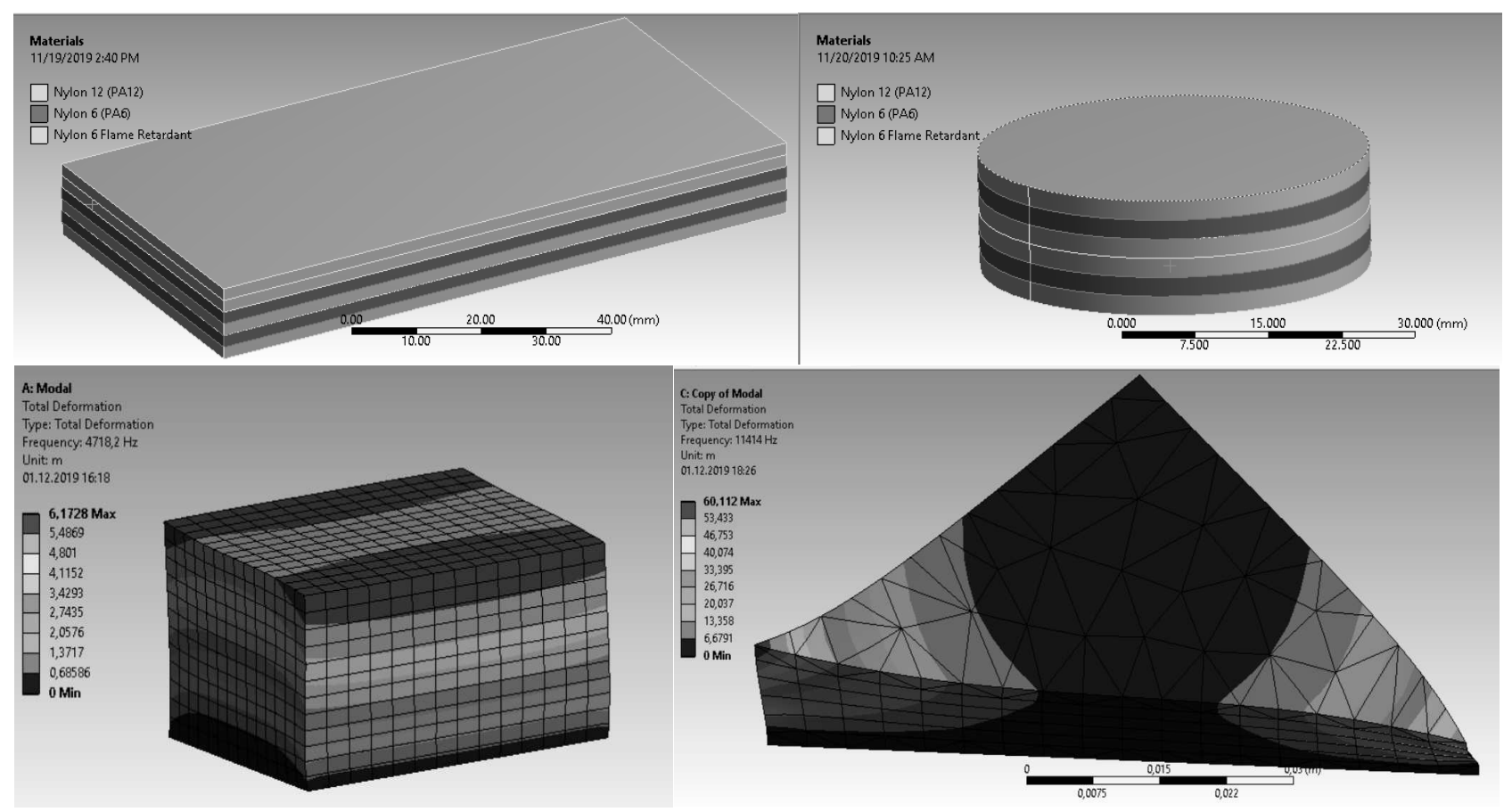

Fig. 2. The second method's geometries and analyses 
2.2 Evaluation of solid-shell finite element simulation-based mechanical property optimization technique

Using stiffeners appear to be one of the solutions to provide the necessary mechanical properties of constructions $[8,9]$. Stiffened plates served to increase the efficacy of structures by increasing the strength to weight ratio of constructions [10]. These structural elements can be considered as plates reinforced by a single or a set of beams or ribs on one or both sides. Therefore, stiffened plates can be defined as the structures that have plate elements, to which loading is applied. It was established that the increase in overall stiffness increases the load-carrying capacity and stability characteristics. Also, stiffened plates minimize material usage and subsequently provide economic and cost-effective design [11].

Referring to the second method of optimization of mechanical properties of materials, three different designs of stiffeners were used to perform buckling analysis on a multi-layered composite flat plate. Their corresponding mechanical properties of each constituent material of composites are listed. The geometrical parameters of the cylindrical object are shown in Tab. 2.

\begin{tabular}{|c|c|c|}
\hline \multirow{3}{*}{$\begin{array}{l}\text { Dimensions } \\
\text { of the cylin- } \\
\text { der }\end{array}$} & $\begin{array}{c}\text { Diameter } \\
(\mathrm{mm})\end{array}$ & 30.28 \\
\hline & $\begin{array}{c}\text { Cross- } \\
\text { sectional } \\
\text { Area } \\
\left(\mathrm{mm}^{2}\right) \\
\end{array}$ & 720.11 \\
\hline & $\begin{array}{l}\text { Length } \\
(\mathrm{mm})\end{array}$ & 100 \\
\hline \multirow{2}{*}{$\begin{array}{l}\text { Dimensions } \\
\text { of the ring- } \\
\text { shaped } \\
\text { stiffener }\end{array}$} & $\begin{array}{c}\text { The outer } \\
\text { diameter } \\
(\mathrm{mm})\end{array}$ & 0.42 \\
\hline & $\begin{array}{c}\text { The inner } \\
\text { diameter } \\
(\mathrm{mm})\end{array}$ & 0.2 \\
\hline \multirow{4}{*}{$\begin{array}{l}\text { Dimensions } \\
\text { of the } \\
\text { longitudinal } \\
\text { stiffener }\end{array}$} & $\mathrm{a}(\mathrm{mm})$ & 0.2 \\
\hline & $\mathrm{b}(\mathrm{mm})$ & 0.42 \\
\hline & $\mathrm{c}(\mathrm{mm})$ & 0.2 \\
\hline & $\begin{array}{l}\text { Length } \\
\text { (mm) }\end{array}$ & 100 \\
\hline
\end{tabular}

The creation of such contacts for the assembling of the stiffeners with the composite flat plate and the cylinder helps to define each element in the complex structure as a distinct element during mesh creation in ANSYS 18.2 Mechanical software. The mathematical expression of the stiffening beams can be represented by Equation (2). It is the constraint function for the stiffening beams subjected to biaxial bending under compression [12].

$$
\frac{N_{s d}}{A f_{y}} \frac{M_{s d, y}}{\gamma_{M 1}}+\frac{W_{p l, y} f_{y}}{\gamma_{M 1}}+\frac{M_{s d, z}}{\frac{W_{p l, z} f_{y}}{\gamma_{M 1}}} \leq 1.0
$$

Where: $W_{p l y,}, W_{p l, z}$ is plastic $1^{\text {st }}$ moments of inertia, $N_{s d}, M_{s d y}, M_{s d, z}$ are computed stress resultants, $f_{y}$ is yield stress, and $\gamma_{\mathrm{M} 1}$ is safety factor equal to1.10.

\section{Discussion}

\subsection{Material optimization based on the mechanical} property of materials.

Ultimately, these results will help to developed more optimized geometry and reduce material use. According to input boundary conditions, the material selection process can be performed. For instance, force distribution is not the same for the geometry and, where high stiffness is needed, 33\% Glass-Filled Nylon Polyamide 6 can be implemented. In the case of the transverse axial loading, Nylon Polyamide 6 Flame Retardant is preferable, and generally, nylon Polyamide 6 Flame Retardant shows good results by indicating a good combination of flexibility and stiffness. Polyetheretherketone and Nylon Polyamide 12 can be chosen on structures where high stiffness is not required. To demonstrate the optimization results by this technique, topology optimization is performed on specially developed geometries, as shown in Fig.3 (a). The geometry is divided into three components, and all of them experience a different type of force because of the structure.

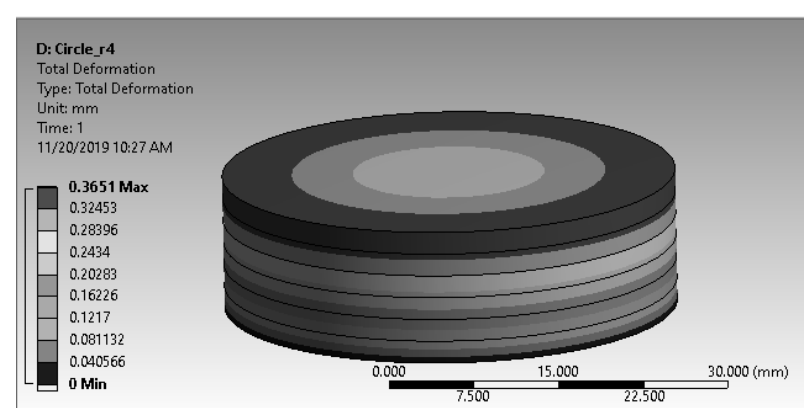

a)

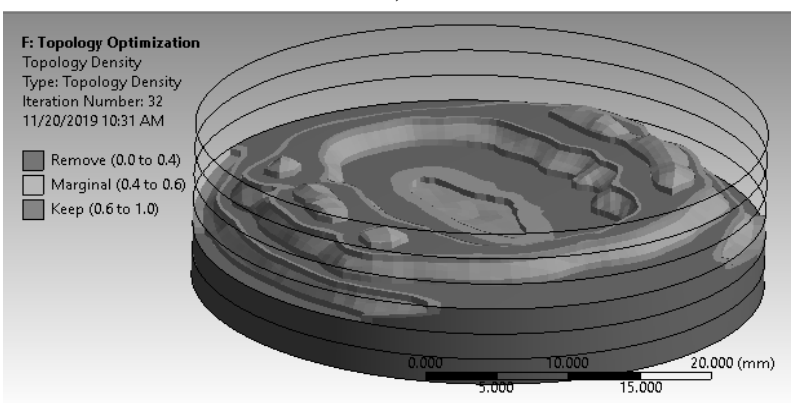

b)

Fig. 3 a) The special geometry developed for material optimization under static structural, b) the final shape after the optimization is performed. Geometry change 
In Fig. 3(b), the final shape of the geometry after material optimization is demonstrated. This specimen is divided into three compartments, and all of them are defined as Nylon Polyamide 12 material. The maximum optimization results for this case are shown in
Table 3. According to them, when the whole geometry is defined with Nylon Polyamide 12, only $21.87 \%$ of mass can be optimized. However, these results can be improved by applying the mechanical propertybased optimization technique. Fig. 4 shows the specimen before and after the optimization.

Tab. 3 Optimization results of geometry with one material only

\begin{tabular}{llll} 
Parameters & Before optimization & After optimization & $\begin{array}{l}\text { Optimized part in per- } \\
\text { cent }\end{array}$ \\
\hline Volume & $7.10 \mathrm{~mm}^{3}$ & $5.54 \mathrm{~mm}^{3}$ & $21.87 \%$ \\
\hline Mass & $6.74 \mathrm{grams}$ & $5.27 \mathrm{grams}$ & $21.87 \%$
\end{tabular}

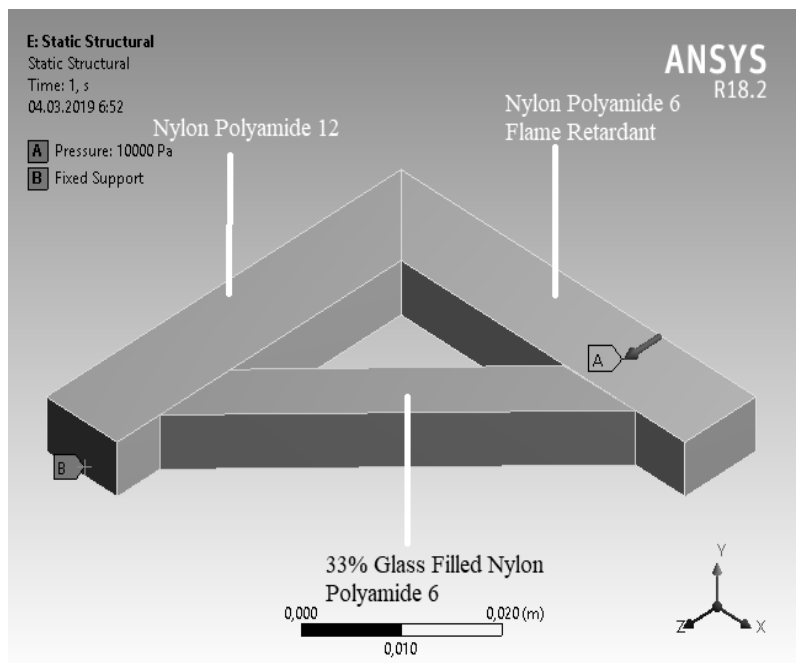

a)

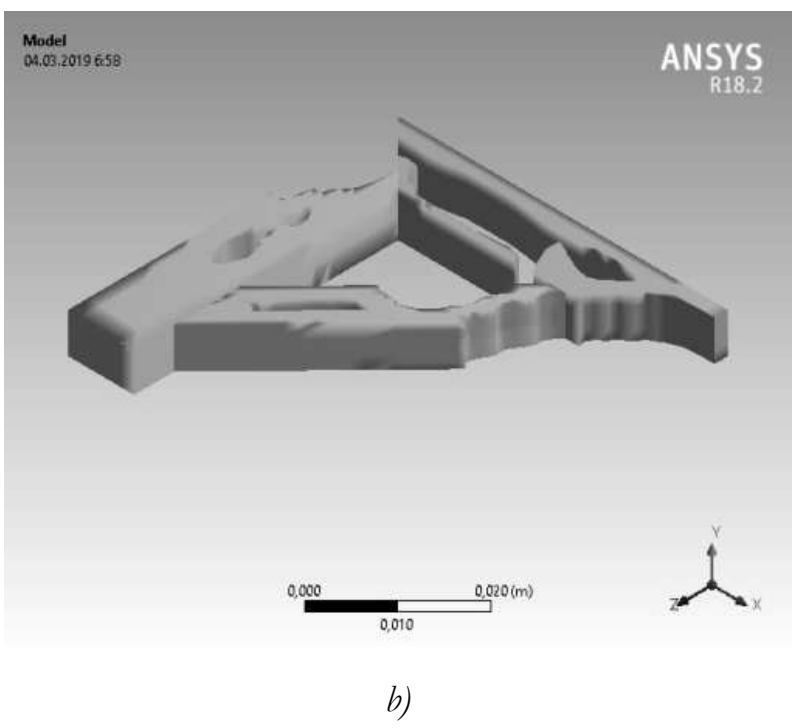

Fig. 4. a) The specimen with different materials at each component. b) The final shape of the specimen after optimization.

Tab. 4 Optimization results of geometry with specially defined materials at specific components

\begin{tabular}{lllc}
\hline $\begin{array}{l}\text { Optimization Parame- } \\
\text { ters }\end{array}$ & Before optimization & After optimization & $\begin{array}{l}\text { Optimized part in per- } \\
\text { cent }\end{array}$ \\
\hline Volume & $7.10 \mathrm{~mm}^{3}$ & $4.18 \mathrm{~mm}^{3}$ & $41.11 \%$ \\
\hline Mass & $8.11 \mathrm{grams}$ & $4.63 \mathrm{grams}$ & $42.85 \%$ \\
\hline
\end{tabular}

The results are considerably improved when some components are defined with suitable material. The optimized amount of material is increased twice. Some materials can better withstand a certain load, and that is the critical point of optimization of this method. The performance is shown in Table 4. Therefore, material analysis by FEA is required to develop a database, and further, to implement materials in an optimized way.

\subsection{Standard deviations and influence of stiffeners}

The standard deviation method was implemented to analyze how deformations of the specimens under buckling load are spread out from the average value.
Graphical representations of standard deviations for the flat plate are shown in Fig. 4. Tab. 5 represents the mean and standard deviation values of the rectangular, L-shaped, and T-shaped stiffeners for the flat plate. These numbers were obtained by calculating the mean values of deformations and using the Equation (3) demonstrated below:

$$
\sigma=\sqrt{\frac{1}{N} \sum_{i=1}^{N}\left(x_{i}-\mu\right)^{2}}
$$

where: $x_{i}$ is individual value; $\mu$ is the average value of the computational results; $N$ is a total number of material optimization techniques using stiffeners, and $\sigma$ is population standard deviation. 
Tab.5 Deviation of the computational results for the flat plate

\begin{tabular}{|c|c|c|c|c|c|c|c|c|c|}
\hline \multirow{2}{*}{$\begin{array}{c}\begin{array}{c}\text { Parame- } \\
\text { ters }\end{array} \\
\text { Material }\end{array}$} & \multicolumn{3}{|c|}{$\begin{array}{l}\text { Implementing } 1,2 \text { and } 3 \\
\text { rectangular stiffeners }\end{array}$} & \multicolumn{3}{|c|}{$\begin{array}{l}\text { Implementing } 1,2 \text { and } 3 \text { L- } \\
\text { shaped stiffeners }\end{array}$} & \multicolumn{3}{|c|}{$\begin{array}{c}\text { Implementing } 1,2 \text { and } 3 \mathrm{~T} \text { - } \\
\text { shaped stiffeners }\end{array}$} \\
\hline & $\begin{array}{l}\text { Mean } \\
\text { value }\end{array}$ & $\begin{array}{l}\text { Stan- } \\
\text { dard de- } \\
\text { viation }\end{array}$ & $\begin{array}{c}\text { Standard } \\
\text { devia- } \\
\text { tion }\end{array}$ & $\begin{array}{l}\text { Mean } \\
\text { value }\end{array}$ & $\begin{array}{l}\text { Stan- } \\
\text { dard de- } \\
\text { viation }\end{array}$ & $\begin{array}{l}\text { Stan- } \\
\text { dard de- } \\
\text { viation }\end{array}$ & $\begin{array}{l}\text { Mean } \\
\text { value }\end{array}$ & $\begin{array}{c}\text { Stan- } \\
\text { dard de- } \\
\text { viation }\end{array}$ & $\begin{array}{l}\text { Standard } \\
\text { deviation }\end{array}$ \\
\hline $\begin{array}{c}\text { Compo- } \\
\text { site ma- } \\
\text { terial } 1\end{array}$ & $\begin{array}{l}1.08 \mathrm{E}- \\
05\end{array}$ & $\begin{array}{l}1.34 \mathrm{E}- \\
05\end{array}$ & $\begin{array}{l}8.10 \mathrm{E}- \\
06\end{array}$ & $\begin{array}{l}1.27 \mathrm{E}- \\
05\end{array}$ & $\begin{array}{l}1.61 \mathrm{E}- \\
05\end{array}$ & $\begin{array}{l}9.38 \mathrm{E}- \\
06\end{array}$ & $\begin{array}{l}1.36 \mathrm{E}- \\
05\end{array}$ & $\begin{array}{l}1.97 \mathrm{E}- \\
05\end{array}$ & 7.42E-06 \\
\hline $\begin{array}{c}\text { Compo- } \\
\text { site ma- } \\
\text { terial } 2\end{array}$ & $\begin{array}{l}1.54 \mathrm{E}- \\
05\end{array}$ & $\begin{array}{l}1.91 \mathrm{E}- \\
05\end{array}$ & $\begin{array}{l}1.16 \mathrm{E}- \\
05\end{array}$ & $\begin{array}{c}1.82 \mathrm{E}- \\
05\end{array}$ & $\begin{array}{l}2.39 \mathrm{E}- \\
05\end{array}$ & $\begin{array}{l}1.25 \mathrm{E}- \\
05\end{array}$ & $\begin{array}{l}1.74 \mathrm{E}- \\
05\end{array}$ & $\begin{array}{l}2.28 \mathrm{E}- \\
05\end{array}$ & $1.20 \mathrm{E}-05$ \\
\hline $\begin{array}{c}\text { Compo- } \\
\text { site ma- } \\
\text { terial } 3\end{array}$ & $\begin{array}{l}1.59 \mathrm{E}- \\
05\end{array}$ & $\begin{array}{l}2.30 \mathrm{E}- \\
05\end{array}$ & $\begin{array}{l}8.70 \mathrm{E}- \\
06\end{array}$ & $\begin{array}{l}1.49 \mathrm{E}- \\
05\end{array}$ & $\begin{array}{l}1.92 \mathrm{E}- \\
05\end{array}$ & $\begin{array}{l}1.06 \mathrm{E}- \\
05\end{array}$ & $\begin{array}{l}1.85 \mathrm{E}- \\
05\end{array}$ & $\begin{array}{c}2.66 \mathrm{E}- \\
05\end{array}$ & $1.04 \mathrm{E}-05$ \\
\hline
\end{tabular}

As can be seen in Fig. 5, the trend of the first composite material is closer to the mean value in all three cases, whereas the other two composite materials show a large deviation when iwntroduced with a single stiffener and significantly fewer deviations when implemented with two and three stiffeners. Therefore, it can be stated that the composition of the material and its constituent materials also play a crucial role in defining the material properties of the printed objects.

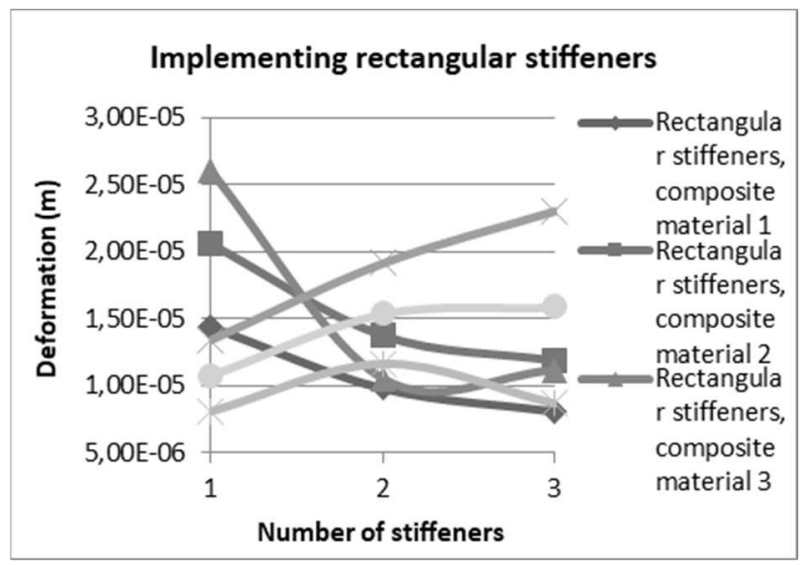

a)

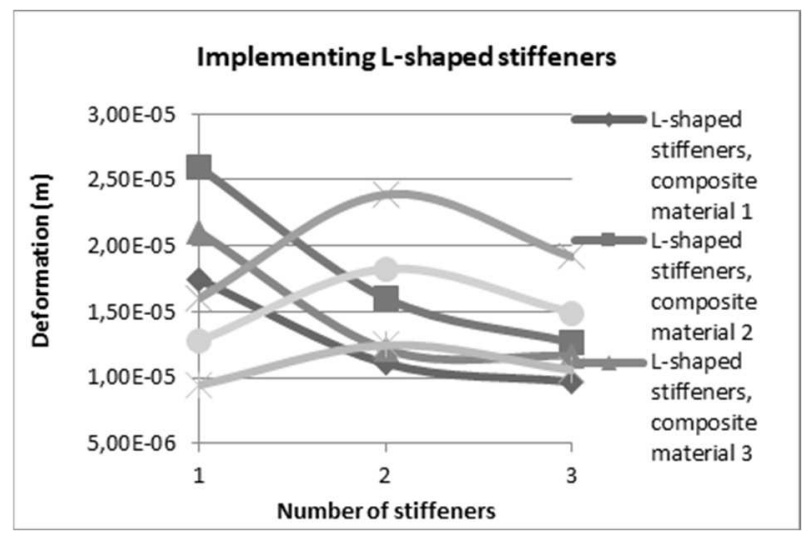

b)

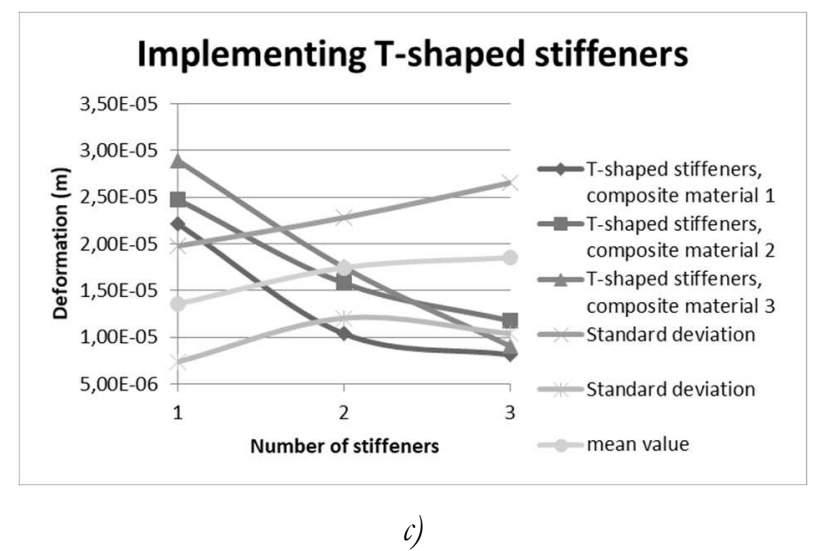

Fig. 5. Standard deviation illustration of the specimen introduced with a) rectangular, b) L-shaped, and c) T-shaped stiffeners

According to Tab. 6, ring and longitudinal stiffener data for the composite materials are within the range of upper and lower standard deviation. Two factors can explain the obtained low deviation: the cylindrical object has small dimensions, and there was a comparison between only two types of stiffeners. For future studies, it is recommended to increase the shapes and numbers of stiffeners implemented to the cylindrical composite material. Also, the dimension of the cylinder can be increased to ease the comparison processes and thus improve the result visualization by tables and graphs.

Fig. 6 demonstrate and compares the impact of 1,2 and 3 stiffeners to the deformation of the flat plate. According to the obtained results, an increase in the number of stiffeners causes a decrease in the deformation of the specimens. However, it should be mentioned that this decrease is negligible, and a single stiffener can be used to provide almost identical results obtained by using 2 or 3 stiffeners. 
Tab. 6 Deviation of the computational results for the cylindrical object

Implementing longitudinal and ring stiffeners

\begin{tabular}{cccc}
\hline Material & Mean value & Standard deviation & Standard deviation \\
\hline Composite material 1 & $2.85 \mu \mathrm{m}$ & $2.86 \mu \mathrm{m}$ & $2.83 \mu \mathrm{m}$ \\
Composite material 2 & $2.57 \mu \mathrm{m}$ & $2.58 \mu \mathrm{m}$ & $2.56 \mu \mathrm{m}$
\end{tabular}

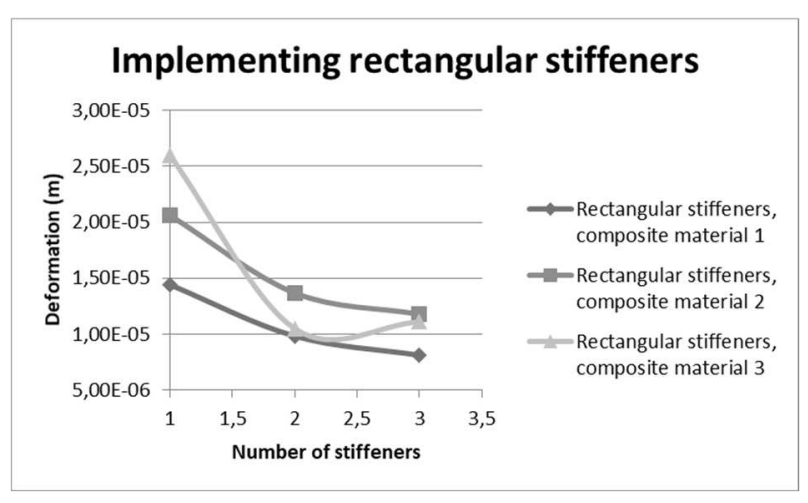

a)

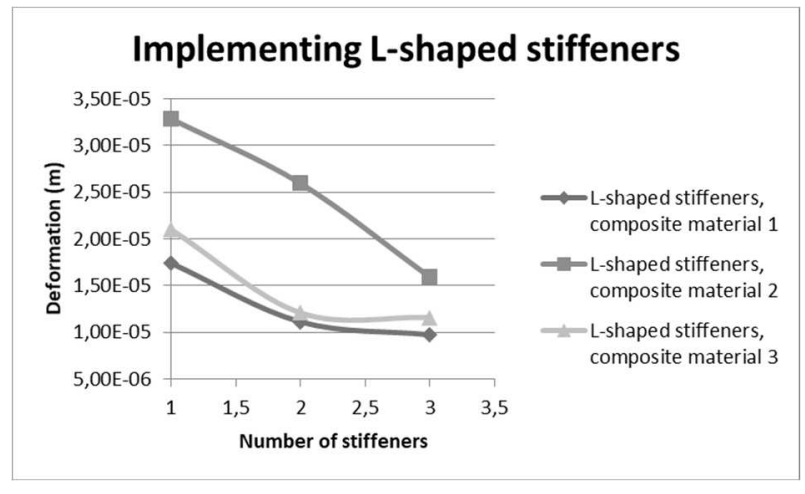

b)

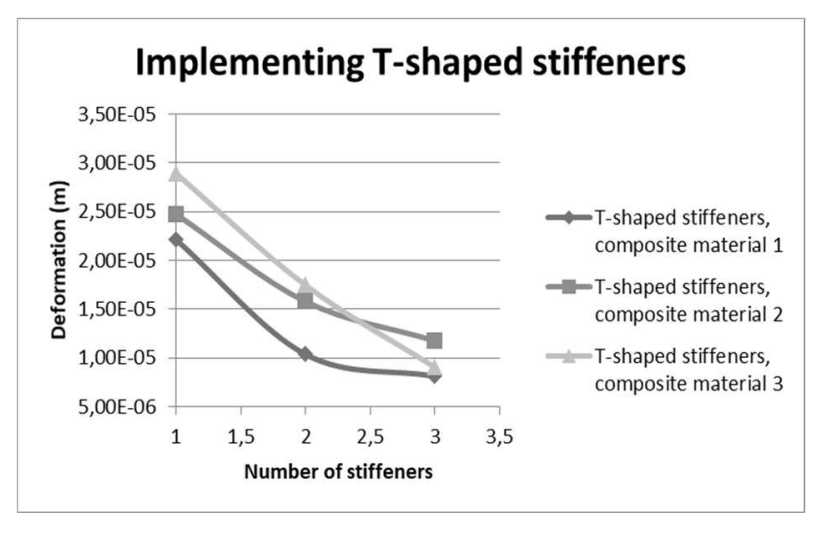

c)

Fig. 6 Implementation of 1, 2 and 3a) rectangular, b) L-shaped and c)T-shaped stiffeners.

Thermoplastic polyamide material was selected for the stiffeners in this study. This material was proven to have superior mechanical properties as compared to other materials used in SLS 3D printing [5]. However, since SLS 3D printing is constantly developing additive manufacturing technology, materials with even better mechanical properties, and cost efficiency can be revealed in the future. Therefore, as an extension of this research, it is proposed to repeat the experiment with the stiffeners that have better mechanical properties as compared to thermoplastic polyamides.

\section{Conclusion}

This research provides important results on material minimization methods for multi-material structures printed by an SLS 3D printer. These methods consist of optimization based on the mechanical property of materials and by stiffening composite specimens. Minimization of the materials requires the creation of comprehensive material property databases. From this database, it can be decided which material should be added or increased in weight percentage to the composite material to achieve desired mechanical properties. The identification of material properties provides the opportunity to optimize the performance of composite materials by embedding the material with the desired mechanical characteristics to the composite. For instance, 33\% Glass-Filled Nylon Polyamide 6 will be added or increased in the weight percentage to the composites to increase the stiffness of the material. Furthermore, the density of the materials also influences the minimization of the composite materials. It is preferred to use a material that has less density and high stiffness.

The analysis based on optimization using the mechanical property prediction method has a substantial impact on the minimization of materials. The second method of minimization was attributed to optimizing by stiffening composite geometry to enhance stiffness characteristics of materials. According to the obtained computational results, it is possible to decrease the deformation of the flat plate and cylindrical object subjected to buckling load by implementing various stiffeners. It should be mentioned that an increase in the number of stiffeners triggers an increase in material stiffness. Ring stiffeners proved to be more effective in comparison with longitudinal stiffeners for the composite cylindrical object subjected to buckling load. Generally, stiffeners optimize the mechanical properties of composite materials by the increasing load-carrying capacity and stability characteristics. Stiffened plates provide material savings and, subsequently, a more economical and cost-effective design. 
Finally, in this research, it was demonstrated how the mechanical property prediction method and reinforcement with stiffeners could minimize the use of composite materials. To comprehensively examine the mechanical properties of the optimized composite materials, these materials should be used to print objects and be tested in the laboratory. After obtaining the correlation between these two results, it will be possible to improve or propose new accurate computation techniques for predicting the mechanical properties of composite materials in the ANSYS program and save additional material usage.

\section{Acknowledgements}

Authors sincerely express their gratitude to Nazarbayev University for the research grant. The award number is 090118FD5327. With the financial support, the research activities are carried out successfully.

\section{References}

[1] SCIART, Designing Light-Weight Parts using Paretoworks, n.d.. [Online]. Available: https:/ / files.solidworks.com/partners/pdfs/p aretoworks-whitepaper.pdf.

[2] FALKENBERG, P., FRANKE, T., FIEBIG, S., VIETOR, T. (2015). Consideration of adhesive joints for a multi-material topology optimization approach, 20th International Conference on Composite Materials, Copenhagen, Denmark, 2015.

[3] TAVAKOLI, R., MOHSENI, S.M. (2014). Alternating active-phase algorithm for multimaterial topology optimization problems: a 115-line MATLAB implementation, Structural and Multidisciplinary Optimization, pp. 621-642, 2014.

[4] YERBOLAT, G., AMANGELDI, S., ALI, M.H., BADANOVA, N., ASHIRBEK, A., ISLAM, G. (2018). Composite Materials Property Determination by Rule of Mixture and Monte Carlo Simulation, v IEEE ICAM, Taiwan, 2018.

[5] MATWEB. Overview of materials for Thermoplastic Polyimide, Carbon Fiber," [Online]. Available: http://www.matweb.com/search/DataSheet.a
spx?MatGUID $=\mathrm{d} 855 \mathrm{dd} 381340493487254652$ 33 f82542.

[6] $\mathrm{MH}$ ALI, A ASHIRBEKOV, N BADANOVA, S AMANGELDI, GAZIZ YERBOLAT (2020). Multi-material Composite-Based SLS Printer Interfaced with GUI, International Journal of Mechanical Engineering and Robotics Research, Vol 9 (1), 2020.

[7] SU, H., JOHNSON, D.L. (1996). Master Sintering Curve: A Practical Approach to Sintering, Journal of the American Ceramic Society, sv. 79, č. 12, pp. 3211-3217, 1996.

[8] JAMEEL, A.N., YOUSUF, L.S., SALIH, A.M. (2014). Buckling Analysis of Stiffened and Unstiffened Laminated Composite Plates, Journal of Engineering, sv. 20, č. 8, pp. 70-87, 2014.

[9] HAREESH, D., VINODO, K. (2013). FEM Analysis on Stiffened plates using ANSYS, Roukela, India, 2013.

[10] KUMAR, P.R., GUPTA, G., SHAMILI, G.K., ANITHA, D. (2018). Linear Buckling Analysis and Comparative Study of Un-stiffened and Stiffened Composite Plate, Materials Today, sv. 5, č. 2, pp. 6059-6071, 2018.

[11] SINGH, D.K., DUGGAL, S.K., PAL, P. (2015). Analysis of Stiffened Plates using FEM - A Parametric Study, International Research Journal of Engineering and Technology, sv. 2, č. 4, pp. 1650-1656, 2015.

[12] THE EUROPEAN UNION (2005). Eurocode 3: Design of steel structures - Part 1-1: General rules and rules for buildings, Brussels, 2005.

[13] LUKÁŠ SMETANKA, JURAJ GERLICI, TOMÁŠ LACK, ZORAN PELAGIĆ (2015). Homogenization of Fibers Reinforced Composite Materials for Simulation Analysis, Manufacturing Technology 2015, 15(5):914920 | DOI: $10.21062 /$ ujep/x.2015/a/12132489/MT/15/5/914.

[14] NOVAKOVA-MARCINCINOVA LUDMILA, JANAK MIROSLAV (2012). Application of Progressive Materials for Rapid Prototyping Technology, Manufacturing Technology 2012, 12(1):7579 | DOI: 10.21062/ujep/x.2012/a/12132489/MT/12/1/75 